\section{Н.В.Станишевская Д.Г.Марченко}

ГУ «Днепропетровская медицинская академия МЗ Украины»

Надійшла: 20.02.2019

Прийнята: 17.03 .2019
DOI: https://doi.org/10.26641/1997-9665.2019.1.88-95

УДК 616-08:616-008.921.1-008.64-021.7.

\section{ВОСПРИЯТИЕ ОБРАЗОВАТЕЛЬНОЙ СРЕДЫ ИНОСТРАННЫМИ СТУДЕН- ТАМИ МЕДИЦИНСКОГО И СТОМА- ТОЛОГИЧЕСКОГО ФАКУЛЬТЕТОВ ДНЕПРОПЕТРОВСКОЙ МЕДИЦИН- СКОЙ АКАДЕМИИ}

Stanishevska N.V. (D), Marchenko D.G. (D) Perception of the educational environment by foreign students of medical and dental faculties of the Dnepropetrovsk Medical Academy.

SI «Dnipropetrovsk Medical Academy of the Ministry of Health of Ukraine», Dnipro, Ukraine

ABSTRACT. Background. Favorable educational environment is the key to successful adaptation of both domestic and foreign students to the requirements of modern training programs. The perception by students of the educational environment requires constant study, since it reflects the internal processes taking place in the student's environment, which characterizes the learning process as a whole. Objective. This investigation was aimed at studying the perception by foreign students of medical and dental faculties of $1^{\text {st }}$ and $2^{\mathrm{d}}$ courses of the Dnipropetrovsk Medical Academy educational environment. Methods. As a method was used Dundee Ready Education Environment Measure (DREEM). DREEM is a questionnaire consisting of 50 statements. All questions are subdivided into five categories: students' perception of learning or learning; teacher perception of pupils or teaching; academic self-perception; educational atmosphere and social self-perception of students. Results. The study involved 200 foreign students. The mean total DREEM score of the educational environment was $139 / 200(70 \%)$ and the majority of students had positive rather than negative perceptions, which can be regarded as quite good conditions of the educational process. Students rated academic self-perception as high $-23.8 / 32$ (74\%). No less appreciated was the perception of learning $-34.7 / 48(72 \%)$. The perception of the educational atmosphere $-32.6 / 48(68 \%)$ and the perception of teaching $-29.9 / 44(68 \%)$ students rated equally and well above average, but social self-perception was reduced -18.5 / $28(66 \%)$. Conclusion. The survey made it possible to assess the perception of the educational environment by foreign medical students of 1 and 2 courses of the Dnipropetrovsk Medical Academy. The educational environment was characterized by the students as positive in general, but with certain disadvantages. Analysis of scores according to all criteria can serve as a basis for the correction of teaching methods, relations between teachers and students, which will contribute to the improvement of the educational process.

Key words: educational environment, perception of learning, academic self-perception, DREEM.

\title{
Citation:
}

Stanishevska NV, Marchenko DG. [Perception of the educational environment by foreign students of medical and dental faculties of the Dnepropetrovsk Medical Academy]. Morphologia. 2019;13(1):88-95. Ukrainian.

DOI: https://doi.org/10.26641/1997-9665.2019.1.88-95

Stanishevska N.V. 0000-0002-3029-050X

Marchenko D.G. 0000-0001-7616-3613

$\triangle$ natstanishevska3536@gmail.com

(C) SI «Dnipropetrovsk Medical Academy of the Ministry of Health of Ukraine», «Morphologia»

\section{Введение}

Развитие системы высшего медицинского образования требует изучения условий образовательной среды, так как они играют очень важную роль, как в эффективности самого обучения, так и в развитии мотивации, формировании необходимых знаний, критического мышления обучающегося.

В качестве инструмента, позволяющего оценить состояние образовательной среды в 1997 году было предложено использование показателя Dundee Ready Education Environment Measure(DREEM). Позднее, в 2012 году был произведен анализ всех исследований, в которых был применен этот метод, при этом упоминалось о 40 публикациях из 20 стран мира. По данным авторов обзора методика изучения образовательной среды DREEM может быть использована в 
диагностических целях, для сравнения между различными группами и сравнения с идеальными / ожидаемыми оценками. Также авторы указывали на то, что DREEM использовался на международном уровне для различных целей и считается полезным инструментом для подобного рода исследований [1].

Следует также отметить, что за последние 20 лет в медицинских учереждениях многих стран проводились исследования образовательной среды с помощью методики Dundee Ready Education Environment (DREEM). Публикации о проведении подобных исследований имеют широкую географию: Великобритания [2], Австралия [3], Индия [4], Китай [5], Германия [6], Ирландия [7], Япония [8], Бразилия [9], Швеция [10], Турция [11], Саудовская Аравия [12], Нигерия [13] и многие другие. Наличие большого количества публикаций за последние 5 лет, в которых отражены результаты применения DREEM в качестве методики изучения образовательной среды свидетельствует об актуальности и соответствии современным требованиям подобной методики.

Одним из таких было исследование в 2015 году, целью которого стала оценка восприятия студентами факультетов медицины и фармации в Рабате (Марокко) образовательной среды с помощью показателя Dundee Ready Education Environment (DREEM). В результате общий балл DREEM составил 90,8 (при максимальном 200), что было расценено как наличие значительного числа проблем в образовательной среде старейшего медицинского факультета Марокко [14].

Подобное исследование в 2016 году в одном из медицинских учебных заведений Индии среди студентов и интернов также показало интересные результаты. Так общий балл DREEM составил 123(при максимуме 200) и все учащиеся имели скорее позитивные, чем негативные академическое самовосприятие $(21,24$ / 32), восприятие атмосферы $(29,21 / 48)$ и восприятие обучения $(28,99$ / 48), в то время как их социальное самовосприятие $(17,48$ / 28) было занижено и восприятие учителей $(26,71$ / 44) также было низким. В заключение исследователи отметили, что все студенты воспринимали свою образовательную среду позитивно. Из положительных моментов по данным авторов все исследованные критерии указывали на то, что учителя были хорошо осведомлены, что у студентов были хорошие друзья, и они были уверены в том, что сдадут экзамены. Проблемными областями, которые наблюдались, были авторитарные учителя, чрезмерный акцент на фактическом обучении, чрезмерно ориентированное на учителей обучение, гнев учителей и необходимость системы поддержки для студентов, испытывающих стресс.

То есть была дана достаточно объективная оценка образовательной среды [4].
Подобные результаты были получены в 2015 году в ходе исследования образовательной среды в школе подиатрии испанского университета Эстремадура. В опросе приняли участие 235 студентов, и по данным авторов в опрашиваемую группу были включены студенты разных курсов в одинаковом количестве. Наряду с обнаруженными некоторыми недостатками в этой школе, в целом учащиеся оценивали образовательную среду положительно по всем пяти категориям DREEM [15].

Методика DREEM позволяет сравнить образовательную среду в разных медицинских учебных заведениях. Так, например, в опубликованных в 2018 году результатах исследования образовательной среды в медицинской школе и школе медсестер в частном университете в Карачи (Пакистан) студенты медсестры оценили более позитивное восприятие их образовательной среды $(127,3 \pm 19,3)$ по сравнению со студентамимедиками (124,6 $\pm 21,3)$. Студенты-медики получили более высокие оценки в области восприятия атмосферы ; в то же время, студентымедсестры получили более высокий балл по академическому самовосприятию. Обе группы поставили более низкие оценки в области восприятия обучения [16].

Любые изменения учебной программы, переходы от традиционного обучения к новейшим методам обучения влечет за собой изменения в восприятии студентами образовательной среды и психологического благополучия, что в свою очередь требует соответствующего контроля. В одной из Саудовских медицинских школ, при переходе от традиционной формы обучения к учебной программе $\mathrm{SBC}$, также было произведено исследование образовательной среды по категориям DREEM. В результате было установлено, что средний суммарный балл DREEM положительного восприятия образовательной среды у учащихся SBC был значительно выше (лучше), чем у учащихся по традиционной учебной программе [12].

\section{Цель}

Образовательная среда (ОС) играет очень важную роль в эффективном обучении студентов. Dundee Ready Education Environment Measure (DREEM) является проверенным инструментом для оценки ОС. Это исследование было направлено на сбор исходной информации о восприятии ОС иностранными студентамимедиками, а также на выявление сильных и слабых сторон, а также возможностей для улучшения ОС.

\section{Материалы и методы}

В исследовании приняли участие студенты медики медицинского и стоматологического факультетов 1-2 курсов Днепропетровской медицинской академии. Всего в анкетировании приняли участие 200 студентов. DREEM представ- 
ляет собою анкету, состоящую из 50 утверждений. Все вопросы подразделяются на пять категорий: восприятие учащимся обучения или обучение (12 утверждений); восприятие преподавателями учеников или преподавание (11 утверждений); академическое самовосприятие (8 утверждений); образовательная атмосфера (12 утверждений) и социальное самовосприятие студентов (7 утверждений). При анкетировании студент оценивает каждое из 50 утверждений по 5бальной шкале, где 4- «Полностью согласен», 3«Согласен», 2-«Не уверен», 1- «Не согласен», 0«Совершенно не согласен». Часть вопросов $(4,8,9,17,25,35,39,48$ и 50$)$ требуют обратного кодирования. Максимальное количество баллов 200 , что соответствует идеальной образователь- ной среде. Результаты DREEM рассматриваются на трех уровнях: 1) отдельные утверждения; 2) подкатегория; 3) общий DREEM. Баллы, полученные от каждого респондента, по каждому утверждению суммируются для каждой категории, для которых определяется средний балл (СБ) и стандартное отклонение $(\mathrm{CO})$.

Результаты и их обсуждение

Средние суммарные баллы и распределение ответов по баллам по показателю DREEM и его пяти подкатегориям: восприятие обучения, восприятие преподавания, академическое самовосприятие, восприятие атмосферы и социальное самовосприятие у 200 студентов-иностранцев 1 и 2 курсов Днепропетровской медицинской академии представлены в следующих таблицах 1-5.

Таблица 1

Восприятие обучения

\begin{tabular}{|c|c|c|c|c|c|c|c|c|}
\hline № & Утверждение & 4 & 3 & 2 & 1 & 0 & СБ & $\mathrm{CO}$ \\
\hline 1 & $\begin{array}{l}\text { Меня поощряют принять участие в заня- } \\
\text { тии. }\end{array}$ & 94 & 81 & 17 & 1 & 7 & 3,25 & 1,02 \\
\hline 7 & Обучение меня стимулирует. & 58 & 84 & 47 & 11 & 0 & 2,85 & 0,97 \\
\hline 13 & Обучение ориентировано на студентов. & 53 & 93 & 36 & 16 & 2 & 2,85 & 0,98 \\
\hline 16 & $\begin{array}{l}\text { Обучение помогает развить мои способ- } \\
\text { ности. }\end{array}$ & 74 & 72 & 28 & 20 & 6 & 2,9 & 1,14 \\
\hline 20 & Преподавание хорошо сфокусировано. & 75 & 79 & 34 & 8 & 4 & 3,03 & 0,98 \\
\hline 22 & $\begin{array}{l}\text { Обучение помогает развить мою уверен- } \\
\text { ность. }\end{array}$ & 76 & 81 & 29 & 9 & 5 & 3,02 & 1,03 \\
\hline 24 & Время обучения расходуется с пользой. & 72 & 81 & 28 & 18 & 1 & 2,98 & 1,01 \\
\hline 25 & $\begin{array}{l}\text { Преподавание переоценивает мою само- } \\
\text { подготовку. }\end{array}$ & 46 & 73 & 56 & 21 & 4 & 2,64 & 1,05 \\
\hline 38 & Я четко понимаю цели обучения курса. & 68 & 79 & 33 & 14 & 6 & 2,9 & 1,08 \\
\hline 44 & $\begin{array}{l}\text { Обучение поощряет меня быть активным } \\
\text { учащимся. }\end{array}$ & 64 & 82 & 35 & 12 & 7 & 2,88 & 1,07 \\
\hline 47 & $\begin{array}{l}\text { Долгосрочное обучение имеет преиму- } \\
\text { щество перед краткосрочным обучением. }\end{array}$ & 56 & 83 & 45 & 12 & 4 & 2,84 & 1 \\
\hline \multirow[t]{2}{*}{48} & $\begin{array}{l}\text { Преподавание в большей степени ориен- } \\
\text { тировано на преподавателя. }\end{array}$ & 45 & 73 & 48 & 25 & 9 & 2,56 & 1,14 \\
\hline & Общий балл & & & & & & $34,7 / 48$ & \\
\hline
\end{tabular}

Общая средняя оценка образовательной среды составила 139, при максимально возможной 200. Большинство студентов имеют скорее положительное, чем отрицательное восприятие, что можно расценивать как достаточно хорошие условия учебного процесса. Максимально высоко студенты оценивают академическое самовосприятие (23,8/32). Восприятие атмосферы (32,6 / $48)$, восприятие преподавания $(29,9 / 44)$ и восприятие обучения $(34,7$ / 48$)$ оцениваются в целом позитивно, в то время как социальное самовосприятие снижено (18,5/28).

Утверждения в нашей анкете располагаются таким образом, что прямо противоположные находятся в начале и конце анкеты, что позволяет сделать более объективную оценку. Например 13 утверждение и 48, которые гласят «Обучение ориентировано на студентов» и «Преподавание в большей степени ориентировано на преподавателя», в нашем исследовании получили 2,85 и 2,56 средних балла соответственно, что указывает на ориентированность учебного процесса в большинстве случаев на студентов, однако небольшая разница в баллах говорит о том, что студенты также часто сталкиваются с самоцентризмом преподавателей. В целом категория восприятия обучения получила суммарный средний балл 34,7 из 48 возможных, что составило $72 \%$.

Интересен анализ ответов студентов в категории восприятия преподавания, то есть, как учащиеся относятся к нашему преподаванию в целом. При достаточно высоком суммарном среднем балле за категорию 29,9(из 44 возможных), 61\% студентов согласились (поставили «4» и «3» балла в 9 утверждении, при среднем балле 
за утверждение 2,67) с тем, что преподаватели авторитарны. Наряду с этим в оценивании утверждений 29 и 40, «Между преподавателями и студентами есть хорошая обратная связь» и «Преподаватели хорошо подготовлены к заняти- ям», 78,5\% и 77,5\% студентов соответственно поставили «3» и «4», что можно расценивать как позитивный момент восприятия качества преподавания.

Таблица 2

Восприятие преподавания

\begin{tabular}{|l|l|c|c|c|c|c|c|c|}
\hline № & \multicolumn{1}{|c|}{ Утверждение } & 4 & 3 & 2 & 1 & 0 & СБ & СО \\
\hline 2 & Преподаватели хорошо осведомлены. & 104 & 76 & 18 & 1 & 1 & 3,37 & 0,77 \\
\hline 6 & $\begin{array}{l}\text { Преподаватели терпеливы со студента- } \\
\text { ми. }\end{array}$ & 84 & 67 & 31 & 16 & 2 & 3,03 & 1,05 \\
\hline 8 & Преподаватели высмеивают студентов. & 39 & 45 & 46 & 51 & 19 & 2,14 & 1,29 \\
\hline 9 & Преподаватели авторитарны. & 47 & 76 & 53 & 21 & 3 & 2,67 & 1,04 \\
\hline 18 & $\begin{array}{l}\text { Преподаватели имеют хорошие навыки } \\
\text { общения со студентами. }\end{array}$ & 78 & 61 & 34 & 22 & 5 & 2,88 & 1,15 \\
\hline 29 & $\begin{array}{l}\text { Между преподавателями и студентами } \\
\text { есть хорошая обратная связь. }\end{array}$ & 76 & 81 & 24 & 15 & 4 & 3,03 & 1,04 \\
\hline 32 & $\begin{array}{l}\text { Преподаватели критикуют конструктив- } \\
\text { о. }\end{array}$ & 40 & 78 & 58 & 16 & 8 & 2,59 & 1,06 \\
\hline 37 & $\begin{array}{l}\text { Преподаватели приводят понятные при- } \\
\text { меры. }\end{array}$ & 64 & 81 & 32 & 14 & 9 & 2,84 & 1,12 \\
\hline 39 & $\begin{array}{l}\text { Преподаватели могут злиться во время } \\
\text { занятия. }\end{array}$ & 37 & 61 & 38 & 28 & 36 & 2,14 & 1,39 \\
\hline 40 & $\begin{array}{l}\text { Преподаватели хорошо подготовлены к } \\
\text { занятиям. }\end{array}$ & 82 & 73 & 31 & 12 & 2 & 3,06 & 1,01 \\
\hline 50 & Студенты раздражают преподавателей. & 50 & 52 & 33 & 21 & 44 & 2,18 & 1,5 \\
\hline & Общий балл & & & & & & $29,9 /$ & \\
\hline
\end{tabular}

Академическое самовосприятие

Таблица 3

\begin{tabular}{|c|c|c|c|c|c|c|c|c|}
\hline № & Утверждение & 4 & 3 & 2 & 1 & 0 & СБ & $\mathrm{CO}$ \\
\hline 5 & $\begin{array}{l}\text { Стратегии обучения, которые работали } \\
\text { для меня раньше, продолжают работать } \\
\text { для меня сейчас. }\end{array}$ & 58 & 92 & 38 & 9 & 3 & 2,95 & 0,95 \\
\hline 10 & $\begin{array}{l}\text { Я уверен в успешном окончании учебно- } \\
\text { го года. }\end{array}$ & 125 & 47 & 22 & 5 & 1 & 3,4 & 0,92 \\
\hline 21 & $\begin{array}{l}\text { Я чувствую, что хорошо готовлюсь к бу- } \\
\text { дущей профессии }\end{array}$ & 79 & 72 & 30 & 16 & 3 & 3 & 1,06 \\
\hline 26 & $\begin{array}{ll}\text { Прошлогодняя подготовка } & \text { помогает } \\
\text { учиться в этом году. } & \end{array}$ & 58 & 89 & 29 & 18 & 6 & 2,83 & 1,08 \\
\hline 27 & Я могу запомнить все, что мне нужно. & 58 & 78 & 46 & 13 & 5 & 2,81 & 1,05 \\
\hline 31 & $\begin{array}{l}\text { Я много узнал об эмпатии в своей про- } \\
\text { фессии. }\end{array}$ & 75 & 67 & 39 & 13 & 6 & 2,92 & 1,1 \\
\hline 41 & $\begin{array}{l}\text { Мои навыки решения проблем хорошо } \\
\text { развиваются }\end{array}$ & 70 & 73 & 38 & 18 & 1 & 2,92 & 1,03 \\
\hline 45 & $\begin{array}{l}\text { Многое из того, что я должен выучить, } \\
\text { кажется важным для карьеры в здраво- } \\
\text { охранении }\end{array}$ & 63 & 84 & 34 & 19 & 0 & 2,92 & 0,97 \\
\hline & Общий балл & & & & & & $23,8 / 32$ & \\
\hline
\end{tabular}


Образовательная атмосфера

\begin{tabular}{|c|c|c|c|c|c|c|c|c|}
\hline № & Утверждение & 4 & 3 & 2 & 1 & 0 & СБ & $\mathrm{CO}$ \\
\hline 11 & $\begin{array}{l}\text { Во время сложных тем обстановка не } \\
\text { напряжена }\end{array}$ & 72 & 80 & 33 & 12 & 3 & 2,99 & 1,01 \\
\hline 12 & $\begin{array}{l}\text { Учебный процесс в академии хорошо } \\
\text { спланирован. }\end{array}$ & 64 & 74 & 34 & 13 & 15 & 2,78 & 1,21 \\
\hline 17 & $\begin{array}{l}\text { Мошенничество - одна из проблем ака- } \\
\text { демии. }\end{array}$ & 40 & 50 & 36 & 33 & 41 & 2,07 & 1,46 \\
\hline 23 & Лекции проходят в хорошей атмосфере. & 60 & 89 & 28 & 18 & 5 & 2,87 & 1,07 \\
\hline 30 & $\begin{array}{l}\text { У меня есть возможности развить навы- } \\
\text { ки межличностного общения. }\end{array}$ & 69 & 69 & 36 & 17 & 9 & 2,82 & 1,17 \\
\hline 33 & Я чувствую себя комфортно на занятии & 85 & 76 & 24 & 12 & 3 & 3,09 & 1,02 \\
\hline 34 & $\begin{array}{l}\text { Занятия и семинары проходят в нена- } \\
\text { пряженной атмосфере. }\end{array}$ & 75 & 75 & 22 & 20 & 8 & 2,9 & 1,16 \\
\hline 35 & Я считаю мой опыт разочаровывающим. & 31 & 39 & 60 & 36 & 34 & 1,96 & 1,3 \\
\hline 36 & Я могу хорошо концентрироваться & 58 & 88 & 38 & 13 & 3 & 2,88 & 0,99 \\
\hline 42 & $\begin{array}{l}\text { Удовольствие от обучения перевешивает } \\
\text { напряжение от обучения. }\end{array}$ & 47 & 75 & 40 & 25 & 13 & 2,55 & 1,2 \\
\hline 43 & $\begin{array}{l}\text { Атмосфера мотивирует меня как учаще- } \\
\text { гося. }\end{array}$ & 60 & 63 & 52 & 16 & 9 & 2,7 & 1,15 \\
\hline \multirow[t]{2}{*}{49} & $\begin{array}{l}\text { Я чувствую, что могу задавать вопросы, } \\
\text { которые хочу. }\end{array}$ & 81 & 72 & 25 & 17 & 5 & 2,99 & 1,1 \\
\hline & Общий балл & & & & & & $32,6 / 48$ & \\
\hline
\end{tabular}

Таблица 5

Социальное самовосприятие

\begin{tabular}{|l|l|c|c|c|c|c|c|c|}
\hline № & \multicolumn{1}{|c|}{ Утверждение } & 4 & 3 & 2 & 1 & 0 & СБ & СО \\
\hline 3 & $\begin{array}{l}\text { Существует хорошая система поддержки } \\
\text { для студентов, которые испытывают } \\
\text { стресс. }\end{array}$ & 46 & 70 & 35 & 30 & 19 & 2,43 & 1,29 \\
\hline 4 & $\begin{array}{l}\text { Я слишком утомлен, чтобы наслаждаться } \\
\text { обучением на этом курсе }\end{array}$ & 46 & 55 & 42 & 29 & 28 & 2,28 & 1,37 \\
\hline 14 & $\begin{array}{l}\text { Мне редко бывает скучно при обучении } \\
\text { на этом курсе. }\end{array}$ & 52 & 60 & 33 & 30 & 25 & 2,38 & 1,37 \\
\hline 15 & $\begin{array}{l}\text { У меня есть хорошие друзья в этом учеб- } \\
\text { ном заведении }\end{array}$ & 89 & 70 & 30 & 6 & 5 & 3,11 & 1,03 \\
\hline 19 & $\begin{array}{l}\text { Я расцениваю мою социальную жизнь } \\
\text { как хорошую }\end{array}$ & 95 & 67 & 23 & 8 & 7 & 3,13 & 1,08 \\
\hline 28 & Я редко чувствую себя одиноким. & 47 & 50 & 46 & 31 & 26 & 2,27 & 1,35 \\
\hline 46 & У меня хорошие условия проживания & 62 & 84 & 41 & 9 & 4 & 2,91 & 1 \\
\hline & Общий балл & & & & & & $18,5 / 28$ & \\
\hline
\end{tabular}

Анализируя категорию академического самовосприятия можно отметить, что 86 \% студентов не сомневаются в успешном окончании текущего учебного года (утверждение 10 «Я уверен в успешном окончании учебного» года получило 3,40 балла). Также 75,5\% и 73,5\% студентов максимально оценили утверждения 21 и 45 (« Я чувствую, что хорошо готовлюсь к будущей профессии» и « Многое из того, что я должен выучить, кажется важным для карьеры в здравоохранении») и получили 3,00 и 2,92 балла соответсвенно. Последнее говорит о том, что две трети студентов считают полученные знания полезными для их профессионального развития.
Характеризуя образовательную атмосферу, обращает на себя внимание то, что 74,5 \% студентов были согласны, что лекции проходят в хорошей атмосфере (соответствующее утверждение получило средний балл 2,87). То же можно сказать и про утверждение «Занятия и семинары проходят в ненапряженной атмосфере», которое получило у 75\% студентов максимальные оценки и средний балл 2,90. Однако только $61,5 \%$ студентов согласились с тем, что «Атмосфера мотивирует меня как учащегося» и средний балл по данному утверждению составил 2,7 .

Категория социального восприятия получи- 
ла наименьший суммарный средний балл по сравнению с другими категориями 18,5 / 28 (66\% от максимального значения). Только 58\% студентов согласились с тем, что в учебном учереждении существует хорошая система поддержки для студентов, которые испытывают стресс ( утверждение 3) и 48,5\% редко чувствуют себя одинокими (утверждение 28). В то же время $79,5 \%$ студентов согласились с тем, что у них есть хорошие друзья в этом учебном заведении (утверждение 15) и $81 \%$ расценивают свою социальную жизнь как хорошую (утверждение 19)

\section{Заключение}

Впервые была произведена оценка восприятия образовательной среды иностранными студентами Днепропетровской медицинской академии по системе DREEM. Интересным изучение этого параметра было именно среди студентов иностранцев, поскольку их адаптация к учебному процессу, особенностям преподавания, отличающихся от тех, которые присущи для их страны проживания, могут значительно влиять на образовательный процесс. В результате анкетирования 200 студентов 1 и 2 курсов стоматологического и медицинского факультетов были получены общая средняя оценка 139/200 (70\%) и большинство студентов имели скорее положи- тельное, чем отрицательное восприятие образовательной среды. Максимально высоко студенты оценили академическое самовосприятие $-23,8$ / 32 (74\%). Высокий балл также был отмечен в категории восприятие обучения-34,7 / 48 (72\%). Восприятие образовательной атмосферы $-32,6$ / 48 (68\%) и восприятия преподавания $-29,9$ / 44 (68\%) студенты расценили в равной степени и значительно выше среднего, однако социальное самовосприятие было снижено -18,5 / 28 (66\%).

Перспективы дальнейших исследований

В дальнейшем необходимо продолжить исследование образовательной среды с целью изучения и постоянного контроля условий учебного процесса, которые находят свое отражение в восприятии, как самого обучения, так и общей атмосферы учебного заведения. Проведя подобное исследование среди студентов-иностранцев начальных курсов, считаем также необходимым изучить восприятие образовательной среды и среди студентов старших курсов, отечественных студентов, что позволит сравнить и проанализировать картину в целом.

Інформація про конфлікт інтересів

Потенційних або явних конфліктів інтересів, що пов'язані $з$ цим рукописом, на момент публікації не існує та не передбачається.

\section{Литературные источники References}

1. Miles S, Leinster SJ, Swift L. The Dundee Ready Education Environment Measure (DREEM): A review of its adoption and use. Medical Teacher.2012;34(9):620-34.

2. Ousey K, Stephenson J, Brown T, Garside J. Investigating perceptions of the academic educational environment across six undergraduate health care courses in the United Kingdom. Nurse education in practice. $2014 ; 14(1): 24-9$.

3. Stormon N, Ford PJ. DREEM-ing of dentistry: Students' perception of the academic learning environment in Australia. European journal of dental education. 2018;18:48-55.

4. Patil AA, Chaudhari VL. Students' perception of the educational environment in medical college: a study based on DREEM questionnaire. Korean journal of medical education. 2016;28(3):281-8.

5. Xu X, Wu D, Zhao X, Chen J, Xia J, Li M, Nie X. Relation of perceptions of educational environment with mindfulness among Chinese medical students: a longitudinal study. Medical education online. 2016;21:30664.

6. Kavukcu E, Burgazli KM, Akdeniz M, Bilgili P, Öner M, Koparan S, Yörümez A. Family medicine and sports medicine students' perceptions of their educational environment at a primary health care center in Germany: using the DREEM questionnaire. Postgraduate medicine. 2012;124(5):143-
50. doi: 10.3810/pgm.2012.09.2585. English.

7. Finn Y, Avalos G, Dunne F. Positive changes in the medical educational environment following introduction of a new systems-based curriculum: DREEM or reality? Curricular change and the Environment. Irish journal of medical science. 2014; 183(2):253-8.

8. Tokuda Y, Goto E, Otaki J, Jacobs J, Omata F, Obara H, Shapiro M, Soejima K, Ishida Y, Ohde $\mathrm{S}$, Takahashi O, Fukui T. Undergraduate educational environment, perceived preparedness for postgraduate clinical training, and pass rate on the National Medical Licensure Examination in Japan. BMC Educ Med. 2010;10:35.

9. Enns SC, Paro HB, Gannam S, Peleias M, Mayer FB, Santos IS, Menezes M, Senger MH, Barelli C, Silveira PS, Martins MA, Zen Tempski P. Medical Students' Perception of Their Educational Environment and Quality of Life: Is There a Positive Association. Academic medicine: journal of Association of American Medicine Colleges. 2016;91(3):409-17.

10. Palmgren PJ, Brodin U, Nilsson GH, Watson R, Stenfors T. Investigating psychometric properties and dimensional structure of an educational environment measure (DREEM) using Mokken scale analysis - a pragmatic approach. BMC medical education. 2018;18(1):235. 
11. Demirören M, Palaoglu Ö , Kemahli S, Özyurda F, Ayhan IH. Perceptions of Students in Different Phases of Medical Education of Educational Environment: Ankara University Faculty of Medicine. Medical education online. 2008;13:8.

12. AlFaris EA, Naeem N, Irfan F, Qureshi R,van der Vleuten C. Student centered curricular elements are associated with a healthier educational environment and lower depressive symptoms in medical students. BMC medical education. 2014; $14: 192$.

13. Buhari MA, Nwannadi IA, Oghagbon EK, Bello JM. Students' perceptions of their learning environment at the College of Medicine, University of Ilorin, Southwest, Nigeria. West African journal of medicine. 2014;33(2):141-5.
14. Belayachi J, Razine R, Boufars A, Saadi A, Madani N, Chaouir S, Abouqal R. Moroccan medical students' perceptions of their educational environment. Journal of educational evaluation for Health Professions. 2015;12:47.

15. Palomo-López $\mathrm{P}$, Becerro-de-BengoaVallejo R, Calvo-Lobo C, Tovaruela-Carrión N, Rodríguez-Sanz D, Elena Losa-Iglesias M, LópezLópez D. Student perceptions of the education environment in a Spanish medical podiatry school. Journal of foot and ankle research. 2018;10:11-4.

16. Farooq S, Rehman R, Hussain M, Dias JM. Comparison of undergraduate educational environment in medical and nursing program using the DREEM tool. Nurse education today. 2018;69:7480 .

Станішевська Н.В., Марченко Д.Г. Сприйняття освітнього середовища іноземними студентами медичного і стоматологічного факультетів Дніпропетровської медичної академії.

РЕФЕРАТ. Актуальність. Сприятливе освітнє середовище $\epsilon$ запорукою успішної адаптації як вітчизняних, так і зарубіжних студентів до вимог сучасних програм навчання. Сприйняття студентами освітнього середовища вимагає постійного вивчення, тому що відображає внутрішні процеси, що відбуваються серед студентів, характеризує навчальний процес в цілому. Мета. Дане дослідження було спрямоване на вивчення сприйняття студентами-іноземцями медичного і стоматологічного факультетів 1 і 2 курсів Дніпропетровської медичної академії умов освітнього середовища. Методи. В якості методики був використаний показник Dundee Ready Education Environment (DREEM). DREEM представляє собою анкету, що складається з 50 тверджень. Всі питання поділяються на п'ять категорій: сприйняття учнем навчання або навчання; сприйняття викладачами учнів або викладання; академічне самосприйняття; освітня атмосфера і соціальне самосприйняття студентів. Результати. У дослідженні взяли участь 200 студентів-іноземців. Середня загальна оцінка освітнього середовища склала 139/200 (70\%) і більшість студентів мали скоріш позитивне, ніж негативне сприйняття, що можна розцінювати як досить хороші умови навчального процесу. Максимально високо студенти оцінили академічне самосприйняття $-23,8$ / 32(74\%). Не менш високу оцінку отримало і сприйняття навчання $-34,7$ / 48(72\%) . Сприйняття освітньої атмосфери -32,6 / 48(68\%) та сприйняття викладання -29,9 / 44(68\%) студенти розцінили однаково, значно вище середнього, проте соціальне самосприйняття було знижено -18,5 / 28(66\%). Підсумок. Проведене дослідження дозволило оцінити сприйняття освітнього середовища студентами-іноземцями 1 і 2 курсів Дніпропетровської медичної академії. Освітнє середовище визначалось студентами як позитивне в цілому, однак воно має і певні недоліки. Аналіз оцінок за всіма критеріями може послужити підставою для корекції методів викладання, відносин між викладачами і студентами, що сприятиме вдосконаленню навчального процесу.

Ключові слова: освітнє середовище, сприйняття навчання, академічне самосприйняття, показник DREEM.

Станишевская Н.В., Марченко Д.Г. Восприятие образовательной среды иностранными студентами медицинского и стоматологического факультетов Днепропетровской медицинской академии.

РЕФЕРАТ. Актуальность. Благоприятная образовательная среда является залогом успешной адаптации как отечественных, так и зарубежных студентов к требованиям современных программ обучения. Восприятие студентами образовательной среды требует постоянного изучения, так как отражает внутренние процессы, происходящие в студенческой среде, характеризует учебный процесс в целом. Цель Данное исследование было направлено на изучение восприятия студентами-иностранцами медицинского и стоматологического факультетов 1 и 2 курсов Днепропетровской медицинской академии условий образовательной среды. Методы. В качестве методики был использован показатель Dundee Ready Education Environment Measure (DREEM). DREEM представляет собою анкету, состоящую из 50 утверждений. Все вопросы подразделяются на пять категорий: восприятие учащимся обучения или обучение ; восприятие преподавателями учеников или преподавание ; академическое самовосприятие ; образовательная атмосфера и социальное самовосприятие студентов. Результаты. В исследовании приняли участие 200 студентов-иностранцев. Средняя общая оценка образовательной среды составила 139/200 (70\%) и большин- 
ство студентов имели скорее положительное, чем отрицательное восприятие, что можно расценивать как достаточно хорошие условия учебного процесса. Максимально высоко студенты оценили академическое самовосприятие $-23,8$ / 32 (74\%). Не менее высокую оценку получило и восприятия обучения-34,7 / 48 (72\%). Восприятие образовательной атмосферы $-32,6$ / 48 (68\%) и восприятия преподавания $-29,9$ / 44 $(68 \%)$ студенты расценили в равной степени и значительно выше среднего, однако социальное самовосприятие было снижено -18,5 / 28 (66\%). Заключение. Проведенное исследование позволило оценить восприятие образовательной среды студентами-иностранцами 1 и 2 курсов Днепропетровской медицинской академии. Образовательная среда была охарактеризована учащимися как положительная в целом, но имеющая и определенные недостатки. Анализ оценок по всем критериям может послужить основанием для коррекции методов преподавания, отношений между преподавателями и студентами, что будет способствовать совершенствованию учебного процесса.

Ключевые слова: образовательная среда, восприятие обучения, академическое самовосприятие, показатель DREEM. 